\title{
Observation of new particle formation in subtropical urban environment
}

\author{
H. C. Cheung, L. Morawska, and Z. D. Ristovski \\ International Laboratory of Air Quality and Health, Queensland University of Technology, G.P.O. Box 2434, \\ Brisbane QLD 4001, Australia
}

Received: 20 August 2010 - Published in Atmos. Chem. Phys. Discuss.: 1 October 2010

Revised: 31 March 2011 - Accepted: 6 April 2011 - Published: 27 April 2011

\begin{abstract}
The aim of this study was to characterise the new particle formation events in a subtropical urban environment in the Southern Hemisphere. The study measured the number concentration of particles and its size distribution in Brisbane, Australia during 2009. The variation of particle number concentration and nucleation burst events were characterised as well as the particle growth rate which was first reported in urban environment of Australia. The annual average $N_{\text {UFP }}, N_{\text {Aitken }}$ and $N_{\text {Nuc }}$ were $9.3 \times 10^{3}$, $3.7 \times 10^{3}$ and $5.6 \times 10^{3} \mathrm{~cm}^{-3}$, respectively. Weak seasonal variation in number concentration was observed. Local traffic exhaust emissions were a major contributor of the pollution $\left(N_{\mathrm{UFP}}\right)$ observed in morning which was dominated by the Aitken mode particles, while particles formed by secondary formation processes contributed to the particle number concentration during afternoon. Overall, 65 nucleation burst events were identified during the study period. Nucleation burst events were classified into two groups, with and without particles growth after the burst of nucleation mode particles observed. The average particle growth rate of the nucleation events was $4.6 \mathrm{~nm} \mathrm{~h}^{-1}$ (ranged from 1.79$7.78 \mathrm{~nm} \mathrm{~h}^{-1}$ ). Case studies of the nucleation burst events were characterised including (i) the nucleation burst with particle growth which is associated with the particle precursor emitted from local traffic exhaust emission, (ii) the nucleation burst without particle growth which is due to the transport of industrial emissions from the coast to Brisbane city or other possible sources with unfavourable conditions which suppressed particle growth and (iii) interplay between the above two cases which demonstrated the impact of the vehicle and industrial emissions on the variation of particle number concentration and its size distribution during the same day.
\end{abstract}

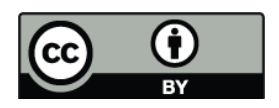

Correspondence to: L. Morawska (1.morawska@qut.edu.au)

\section{Introduction}

Understanding the formation process of atmospheric particles is vital because of the significant impact of particulate matter on human health and climate change (Charlson et al., 1992; Donaldson et al., 1998). Atmospheric particles can be formed by nucleation process via a number of different mechanisms (e.g. Kulmala, 2003; Kulmala et al., 2004), such as binary nucleation (involving $\mathrm{H}_{2} \mathrm{SO}_{4}$ and water vapour), ternary nucleation (involving $\mathrm{NH}_{3}, \mathrm{H}_{2} \mathrm{SO}_{4}$ and water vapour) and ion-induced nucleation for charged particles, depending on the environmental conditions. To date, numerous studies have been conducted in different locations, in order to investigate particle formation processes in different environmental settings, including the free troposphere (e.g. Weber et al., 2001), boreal forests (e.g. Vehkamäki et al., 2004) and coastal areas (e.g. O'Dowd et al., 1999; Lee et al., 2008). However, most of these studies focused on particle formation in rural settings and in colder climates, with very few studies conducted in urban environments, especially in the Southern Hemisphere (Kulmala et al., 2004). A limited number of studies were conducted in continental (e.g. Woo et al., 2001; Moore et al., 2007; Wu et al., 2008) and coastal (Pey et al., 2008; Rodríguez et al., 2008; Fernández-Camacho et al., 2010; Pérez et al., 2010) urban areas. These studies examined the variation of particle number concentration in urban environments. The major influence on particle number concentration was vehicle exhaust emissions during the traffic peak hours (e.g. Pey et al., 2008; Pérez et al., 2010) and new particle formation by photochemical reactions (e.g. Pey et al., 2009), as well as the influence of power plant and industrial emissions from an area upwind from the urban site (Gao et al., 2009). The few examples include studies on particle formation associated with natural emissions from a Eucalypt forest in South-East Australia (Ristovski et al., 2010; Suni et al., 2008), which concluded that natural emissions were in fact a source of particle formation. In addition, new particle

Published by Copernicus Publications on behalf of the European Geosciences Union. 
formation was observed in the coastal area of Eastern Australia (Johnson et al., 2005; Modini et al., 2009), the result of which showed that new particles were formed by the condensation of sulphate and/or organic vapours onto sulphate clusters to form an observable particle. Guo et al. (2008) conducted a short-term intensive study on particle formation in the rural environment of Eastern Australia, in which particle formation was suggested to be influenced by the photochemical processes of the urban air plume. The findings of Guo et al. (2008) provided an insight to the impact of urban pollution on nucleation processes. For the urban environment, Mejía et al. (2009) characterised the favourable atmospheric conditions for nucleation burst events in a coastal urban area in Brisbane, which is the only nucleation study conducted in an urban area in the Southern Hemisphere to date. The study showed that the nucleation events mostly occurred during the summer and it also suggested cleaner air masses of a local origin mixing with traffic exhaust emission after the events. However, Mejía et al. (2009) did not investigate the nucleation growth process after the nucleation burst events, and thus particle formation parameters, such as particle growth rate, are not available for the urban environment in Southern Hemisphere. The particle growth rate is an important factor for the calculation of climate forcing.

To further investigate the characteristics of the particle formation processes in a subtropical urban environment, we conducted a one year-long measurement of the size distribution of particles in the size range $4-110 \mathrm{~nm}$, at an urban area of Brisbane, Australia. The aim of this study was to characterise the temporal variation of particle number concentration, and to explain the controlling factors that influenced new particle formation processes in the subtropical urban environment.

\section{Methodology}

\subsection{The topography and meteorology of Brisbane region}

Brisbane is the capital city of the state of Queensland, Australia, located at $27^{\prime} 30^{\circ} \mathrm{S}$ and $153^{\circ} \mathrm{E}$. Brisbane city is surrounded by mountains from south to north, and faces the Pacific Ocean to the East. It is the fastest growing urban region in Australia (2 million inhabitants). The major pollution sources affecting the CBD region are traffic exhaust emissions generated in the inner city, and aircrafts, ships and industrial emissions transported from the lower reaches of Brisbane River, approximately $15-18 \mathrm{~km} \mathrm{NE}$ of the CBD. The Brisbane River meanders through the Brisbane region.

Morawska et al. (1998) provided a description of the wind patterns in the Brisbane region, which are mostly governed by synoptic flows from the SE. A NE sea breeze is also a daily feature throughout the year. In addition, an overnight SW drainage flow from the mountain range to the West car-

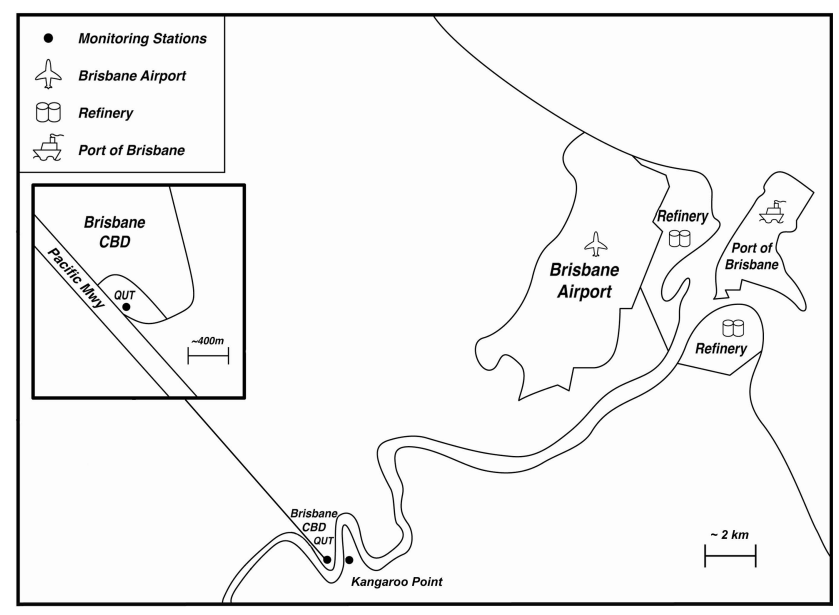

Fig. 1. Map of Brisbane.

ries air parcels from the plateau region and the Western coastal plain towards the city. On the rare occasion when gradient winds are blowing from the NW, the combination of the light synoptic NW flow and the overnight SW drainage flow can sufficiently delay the onset of the sea breeze to cause recirculation of the city emissions, leading to photochemical smog events.

\subsection{The QUT study site}

The measurements were conducted at the International Laboratory of Air Quality and Health (ILAQH), Queensland University of Technology (QUT), which is within the CBD of Brisbane (Fig. 1). The monitoring site was about $10 \mathrm{~m}$ a.g.l. on the top floor of a QUT campus building, located to the SE of the city centre, with a major highway (the Pacific Motorway) situated along the SW side of the campus. Therefore, the pollution associated NE winds could be attributed to industrial emissions (from the airport, oil refinery and Port of Brisbane), while the pollution associated with S to NW winds could be attributed to local traffic exhaust emissions.

\subsection{Measurement techniques}

The size distribution of ultrafine particles (UFPs) was measured at the QUT monitoring site from 1 January to 31 December 2009. Particle size distribution in the range 4$110 \mathrm{~nm}$ was measured by a Scanning Mobility Particle Sizer (SMPS) system, which consisted of two parts, an Electrostatic Classifier (EC) (TSI 3080) and a Condensation Particle Counter (CPC) (TSI 3781). The EC was equipped with a nano-differential mobility analyser, which can separate the poly-disperse particles into selected mono-disperse particles according to their particle mobility. The number concentration of the mono-disperse particles was then counted by the CPC. Each ambient sample was drawn into the SMPS system from outside the building through a $0.635 \mathrm{~cm}$ 
(inner diameter) conductive tube and a sampling duration of 5 min was adopted for each particle size distribution sample. Multiple charge correction was applied to the particle size distribution measurements by using an internal algorithm from the Aerosol Instrument Manager Software.

In this study, the size distribution data was classified into three groups, (i) UFPs, including particles ranging from 4$110 \mathrm{~nm}\left(N_{\mathrm{UFP}}\right)$; (ii) Aitken mode with particles $\left(N_{\text {Aitken }}\right)$, which ranged from $30-110 \mathrm{~nm}$; and (iii) nucleation mode particles, which were $<30 \mathrm{~nm}$ ( $\left.N_{\text {nuc }}\right)$. In addition to the above particle measurements, meteorological parameters, including wind speed and direction, temperature and relative humidity (RH) were monitored at Kangaroo Point (1 km East of QUT) by the Queensland Bureau of Meteorology. The QUT and Kangaroo Point sites were not blocked by high rise buildings and therefore the use of wind data measured at Kangaroo Point was representative of the synoptic wind direction of the study region. It should be noted that global solar radiation was measured at the Queensland Environmental Protection Agency site (Rocklea), about $10 \mathrm{~km}$ south of QUT.

\subsection{Data processing and analysis}

In this study, the raw particle size distribution and meteorological data were synchronised into $10 \mathrm{~min}$ averaged data for data analysis and figure plotting. According to Mejía et al. (2007) the lower limit of the particle size distribution dataset was set to $1 \mathrm{~cm}^{-3}$. The upper limit was set to $5 \times 10^{5} \mathrm{~cm}^{-3}$. Some data were removed from the database based on several criteria such as (i) zero value for particle concentration; (ii) particle concentration higher than $5 \times 10^{5} \mathrm{~cm}^{-3}$ and (iii) data collected during instrument malfunction. During the one year measurement campaign, $28 \%$ of the data was removed based on the above data reduction procedures and due to instrument maintenance. Correlations between the parameters were tested using the Pearsonproduct moment correlations test with a $95 \%$ confidence level $(p<0.05)$. The linearity of the tested parameters was indicated by Pearson's coefficient, $r$, with a perfect linear correlation between two parameters indicated by an $r$ value close to 1 .

\section{Results and discussion}

\subsection{Overall results}

The overall average concentration of ultrafine particles $\left(N_{\text {UFP }}\right)$, Aitken mode $\left(N_{\text {Aitken }}\right)$ and nucleation mode $\left(N_{\text {nuc }}\right)$ measured in this study were $9.3 \times 10^{3}\left( \pm 15.3 \times 10^{3}\right)$, $3.7 \times 10^{3}\left( \pm 5.1 \times 10^{3}\right)$ and $5.6 \times 10^{3} \mathrm{~cm}^{-3}\left( \pm 12.6 \times 10^{3}\right)$, respectively. The values obtained in this study are similar to those observed in similar environments in Northern Europe (Hussein et al., 2004). The few studies conducted in
Southern European countries showed much higher concentrations than those which were reported in this study (Pey et al., 2008; Rodríguez et al., 2008; Fernández-Camacho et al., 2010). Similar values of $N_{\text {Aitken }}$ and $N_{\text {nuc }}$ were obtained in the urban areas of Helsinki, Finland, which were $4.0 \times 10^{3}-6.5 \times 10^{3} \mathrm{~cm}^{-3}$ and $5.5 \times 10^{3}-7.0 \times 10^{3} \mathrm{~cm}^{-3}$, respectively (Hussein et al., 2004). The $N_{\text {UFP }}$ measured in Brisbane was relatively lower than that in other coastal urban areas, including the Yangtze River Delta, China (Gao et al., 2009), Barcelona (Pey et al., 2008) and Huelva and Santa Cruz de Tenerife, Spain (Rodríguez et al., 2008; FernándezCamacho et al., 2010), which were $28.5 \times 10^{3}, 14.2 \times 10^{3}$ and $22.0-26.3 \times 10^{3} \mathrm{~cm}^{-3}$, respectively.

The results of this study were also compared to those of a previous study conducted in the Brisbane urban region from 1995 to 2000 (Mejía et al., 2007). The $N_{\text {UFP }}$ and $N_{\text {nuc }}$ measured in this study were about $8 \%$ and $60 \%$ higher than those measured by Mejía et al. (2007), being $8.6 \times 10^{3} \mathrm{~cm}^{-3}$ (for particles in the size range $15-100 \mathrm{~nm}$ ) and $3.5 \times 10^{3} \mathrm{~cm}^{-3}$ (for particles in the size range $15-30 \mathrm{~nm}$ ), respectively. In relation to $N_{\text {nuc }}$, it should be noted that the nucleation mode particle concentration in this study covered particles in the size range $4-30 \mathrm{~nm}$, and therefore, it is expected to be higher than the earlier result reported by Mejía et al. (2007).

The seasonal variation of particle number concentrations is depicted in Fig. 2. The Pearson's coefficients, $r$, between particle number concentration of different modes and temperature were calculated which ranged from $0.00-0.03$, which indicates that there was no statistical seasonal variation in particle concentrations. This result is similar to that presented by Mejía et al. (2007) for the same study region, however larger variations in particle number concentrations were observed in each mode during the summer season, as reflected by the large interquartile range (Fig. 2).

Figure 3 shows the diurnal variation of particle number concentration for different modes with the diurnal variations of temperature and relative humidity also plotted. Two peaks were observed for UFP during the day, the first of which occurred from around 06:00 a.m. to 08:00 a.m., possibly due to traffic exhaust emissions during the morning peak hours (from around 06:00 a.m. to 08:00 a.m.) in Brisbane urban region (Mejía et al., 2007). The second peak, which is much more important, was observed from around 12:00 noon to 03:00 p.m., and this may be due to the formation of new particles. During the period of UFP morning peak, it was suggested that the Atiken mode particles contributed by the direct diesel and petrol engine emissions, which produce particles in the size range of about $20-130 \mathrm{~nm}$ and $20-60 \mathrm{~nm}$, respectively (Morawska et al., 2008). Also the nucleation mode particles could be formed during the dilution and cooling of engine exhausted sulphuric and organic vapours by condensation onto sulphur clusters (Meyer and Ristovski, 2007). During the period of the second UFP peak, a nucleation mode peak was also observed associated with highest level of solar radiation, which implies that new particles were 


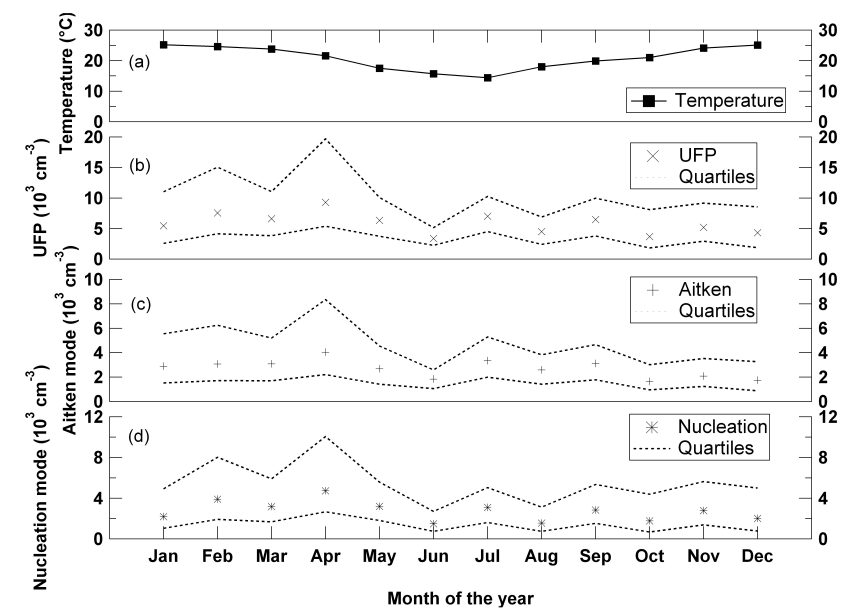

Fig. 2. Monthly variations of (a) mean temperature, and particle number concentration of ultrafine (UFP) (b), Aitken mode (c) and nucleation modes particles (d). The median number concentrations and the 1 st and 3 rd quartiles are presented.

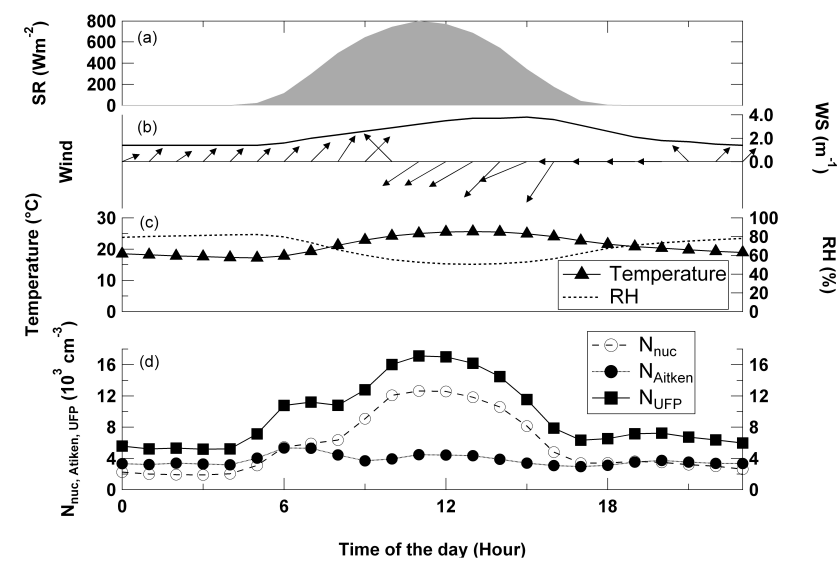

Fig. 3. Diurnal variation of (a) averaged solar radiaiton, (b) averaged wind direction/speed, (c) averaged temperature and $\mathrm{RH}$, and (d) averaged UFP, nucleation mode and Aitken mode particle concentrations.

produced during the early afternoon by photochemical reactions.

\subsection{Relationship between particle number concentrations and meteorological parameters}

\subsubsection{Temperature, relative humidity and solar radiation}

From Fig. 3 it can be seen that temperature and relative humidity display an anti-correlation, whereby increases in temperature were associated with decreases in relative humidity. The influences of temperature on particle number concentration were not confirmed in previous studies. Some studies found that high particle concentration was related to rela-

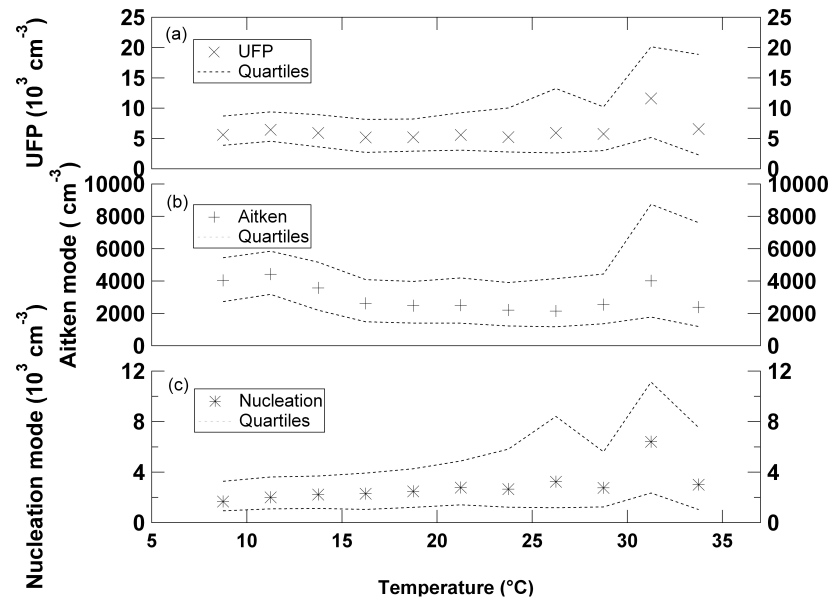

Fig. 4. Particle number concentrations of (a) ultrafine (UFP), (b) Aitken mode and (c) nucleation mode particles and their variation as a function of temperature. The median number concentrations and the 1st and 3rd quartiles are presented.

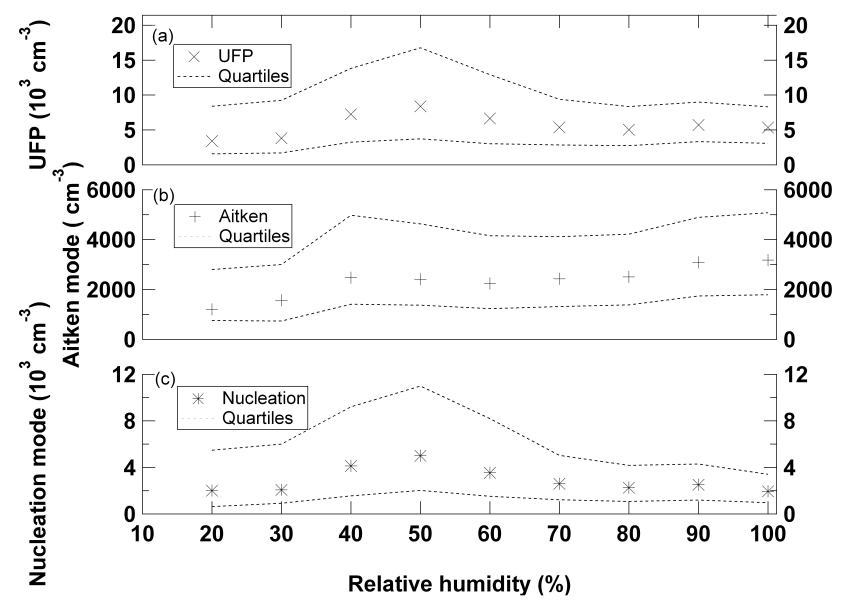

Fig. 5. Number concentrations of (a) ultrafine (UFP), (b) Aitken mode and (c) nucleation mode particles and their variation as a function of relative humidity. The median number concentrations and the 1 st and 3rd quartiles are presented.

tively high temperatures (e.g. Kim et al., 2002), whilst others found that they were associated with relatively low temperatures (e.g. Olivares et al., 2007). In this study, a weak correlation between particle number concentrations and temperature was observed $(r=0.36-0.53 ; p<0.01)$, however higher variations in $N_{\text {UFP }}, N_{\text {Aitken }}$ and $N_{\text {nuc }}$ were observed during warmer and lower humidity conditions (Figs. 4 and 5 ). The highest number concentrations of all particle sizes were associated with temperature around $32{ }^{\circ} \mathrm{C}$. The peaks of $N_{\text {Aitken }}$ and $N_{\text {nuc }}$ observed in the early afternoon (under high temperature conditions) suggested that the contribution by new particle formation processes was the greatest, followed by particle growth to larger particles. In addition, another peak 
of $N_{\text {Aitken }}$ was observed with temperature around $10^{\circ} \mathrm{C}$ (see Fig. 4). Also higher $N_{\text {Aitken }}$ concentrations were observed under humid conditions (see Fig. 5). This result may be due to enhanced coagulation and condensation effects under high humidity conditions.

In some cases, temperature data can not directly reflect the strength of photochemical activities which occurred on warm cloudy days. In addition, condensation vapour $\mathrm{H}_{2} \mathrm{SO}_{4}$ production was related to the solar radiation (Ristoviski et al., 2010). Therefore, solar radiation was used to indicate the reactivity of photochemical reactions. The particle number concentration did not show a clear relationship with the ambient temperature. In contrast, a positive relationship between particle number concentration and solar radiation data was observed $(r=0.92-0.98 ; p<0.01)$. This result showed that the $N_{\text {nuc }}$ was related to the photochemical reactions.

\subsubsection{Wind direction and speed}

Figure 6 shows the particle number concentration for different particle sizes under different wind directions. For UFP, a sharp peak was associated with ENE wind directions, and a lower broad peak was associated with SSE to WNW wind directions. An interesting result was also obtained when dividing the data into Aitken and nucleation modes. The sharp peak was observed in both of these two modes, however the broad peak was only observed in the Aitken mode. From Fig. 1, it can be seen that the Brisbane Airport, oil refinery and Port of Brisbane were all located to the NE of the monitoring site, whilst the CBD and Pacific Motorway were located to the NW and SW of the monitoring site. Therefore, it is likely that the nucleation mode particles were contributed by the industrial sources located to the NE, while the Aitken mode particles were emitted from both industrial and vehicle emission sources, as well as the coagulation/condensation of smaller particles under humid conditions (see Sect. 3.2.1), which will contribute to the accumulation mode. In addition, air masses blowing from the marine boundary (NE to SE directions) were relatively clean. However, the inland air mass from the NE direction was contaminated by industrial emissions. This interpretation can be supported by higher $N_{\text {UFP }}$ in north-easterly air masses and lower $N_{\text {UFP }}$ in easterly or south-easterly air masses (clean maritime air masses, which are thought to be much less loaded in gaseous precursors). To better illustrate the directional dependence of the $N_{\mathrm{UFP}}$, $N_{\text {Aitken }}$ and $N_{\text {nuc }}$ a wind rose plot of particle number concentration superimposed over the location map is shown in the Supplement (Fig. S1).

In general, a negative correlation was observed between UFP concentration and wind speed, indicated by a Pearson coefficient of $r=-0.97(p<0.01)$. Higher particle number concentration was associated with lower wind speeds (see Fig. 7), which can be explained by the stronger dispersion associated with high wind speeds (Hussein et al., 2006). Similar results were also observed for Aitken and nucleation

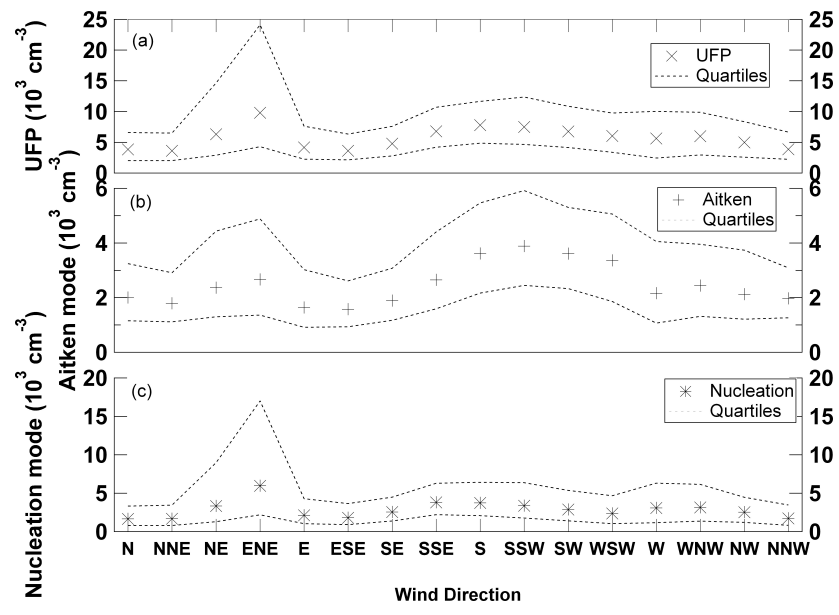

Fig. 6. Number concentration of (a) ultrafine (UFP), (b) Aitken mode and (c) nucleation mode particles and their variation as a function of wind direction. The median number concentrations and the 1 st and 3rd quartiles are presented.

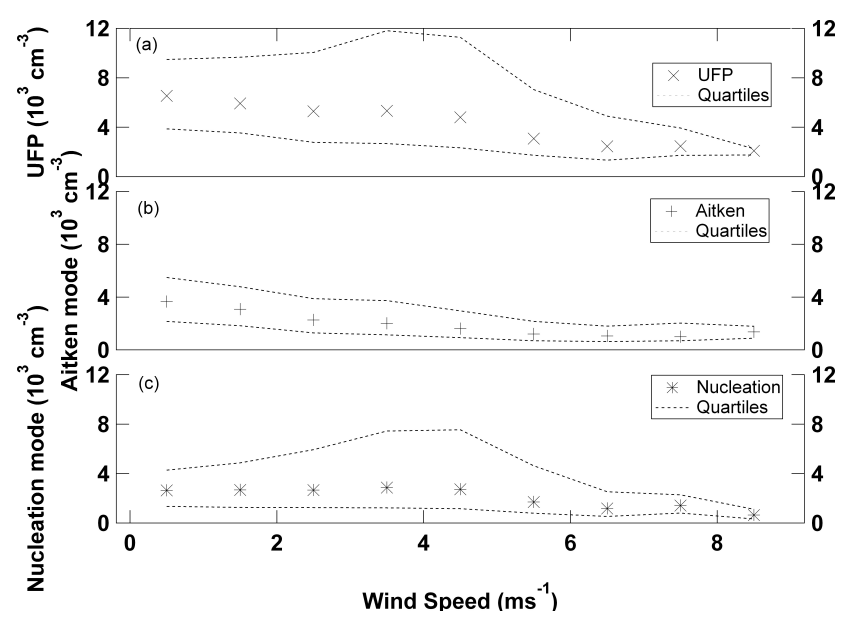

Fig. 7. Number concentration of (a) ultrafine (UFP), (b) Aitken mode and (c) nucleation mode particles and their variation as a function of wind speed. The median number concentrations and the $1 \mathrm{st}$ and 3rd quartiles are presented.

mode particles. In addition, a larger variation of $N_{\text {nuc }}$ was associated with the moderate wind speed $\left(\sim 4 \mathrm{~ms}^{-1}\right) . N_{\text {nuc }}$ usually reached its daily peak value during early afternoon and the corresponding wind speed was $\sim 4 \mathrm{~ms}^{-1}$ (see Fig. 3).

\subsection{Particle formation in subtropical urban atmosphere}

\subsubsection{Classification of nucleation events}

The general definition of a nucleation event is a two-phase process involving the burst of observed nucleation particles and the growth of these particles into accumulation mode by condensation and/or coagulation (Kulmala et al., 2004). To illustrate the nucleation event, a "banana" shape should be 


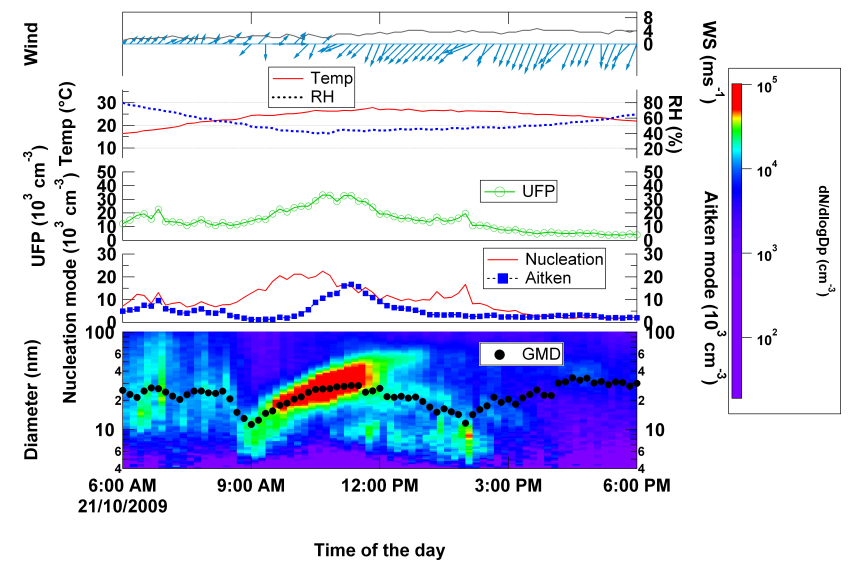

Fig. 8. The time series of nucleation events observed at QUT on 21 October 2009. From bottom to top, the parameters are: (i) Geometric median diameter (GMD) and contour plot of size distribution; (ii) Particle number concentration of nucleation and Aitken mode particles; (iii) Particle number concentration of ultrafine particles (UFP); (iv) Temperature and relative humidity; and (v) wind direction and speed.

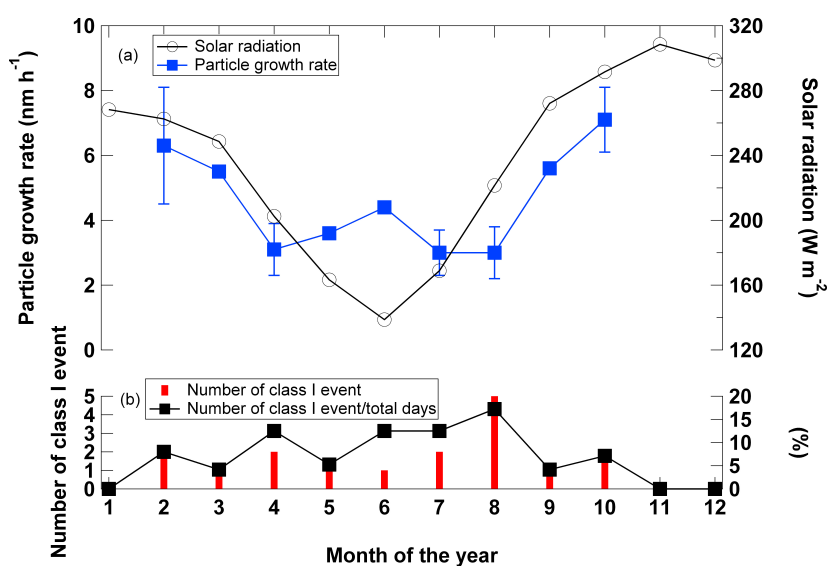

Fig. 9. Seasonal variation in (a) particle growth rates and solar radiation and (b) number of class I event and the precentage ratio of class I event to total sampling days.

observed in the contour plot of particle size distribution. The example of a nucleation event is shown in Fig. 8. Usually the lowest $N_{\text {nuc }}$ is observed in the early morning, and then it begins to increase at around 09:00 a.m. The geometric median diameter (GMD) of the measured particles grows into an Accumulation mode during the day and the evolvement of the particle size curve is often compared to a banana shape.

A number of nucleation events were observed during this study, which were classified into different groups (Class Ia/b and II) according to the classification scheme developed by Dal Maso et al. (2005). Class Ia/b events are defined as those events where the particle growth rate can be determined. A typical Class Ia event demonstrates clear and strong particle formation events with little or no pre-existing particles obscuring the observation of the newly formed mode, while a Class Ib event is any other event where the particle growth rate can be determined. Class II events are defined as events where the banana shape still observable, but the data fluctuates to such an extent that formation rate calculation is impractical.

In the urban environment, nucleation burst events have been observed with and without particle growth (Park et al., 2008; Gao et al., 2009). For example, in addition to nucleation events, we occasionally observed increases in nucleation mode particle concentration during the daytime, where the particles did not grow into larger particles (indicated by the near constant GMD value during the event period). We defined this kind of event as a nucleation burst event, and a total of 65 burst events were identified. A more detailed discussion about the occurrence of nucleation events, both with and without particle growth, is provided in Sects. 3.3.2 and 3.4 below.

\subsubsection{Growth rate during nucleation events}

During this study, there were several gaps in the dataset due to instrument malfunction/maintenance. For example, if there were more than $3 \mathrm{~h}$ of missed data between 08:00 a.m. to $06: 00 \mathrm{p} . \mathrm{m}$. (the period during which the nucleation usually occurs), this was not counted as a valid daily dataset. After the removal of invalid daily datasets, a total of 252 days of data were counted.

Figure 9 shows the monthly averaged particle growth rate and solar radiation, as well as the monthly occurrence of nucleation events. This data provided information regarding the influence of photochemical activity on particle formation in Brisbane. Higher particle growth rate was found to be associated with higher solar radiation and the results showed a positive relationship $(r=0.76, p<0.05)$ between the particle growth rate of nucleation events and solar radiation. Similar findings were obtained in previous studies, which showed that particle growth rates were associated with the strength of solar radiation (e.g. Kulmala et al., 2004; Vehkamäki et al., 2004). The number of nucleation events classified as Class Ia, Ib, and II were 4,13 , and 23 , respectively. The nucleation events (Class I and II) occurred throughout most of the year, except in November, and only one Class II event was observed in December. Although infrequent nucleation events were observed during November and December, the nucleation bursts (without particle growth) were found to be closely associated with $\mathrm{NE}$ wind directions. In addition to the seasonal variation of temperature, the dominant wind direction measured during November and December was different to other months. NE winds dominated during these warmer months, while the main wind direction was from the SE-SW during other months. The influence of wind direction on the nucleation events will be discussed in the case studies below. The mean growth rate for the nucleation events was 
calculated by the slope of GMD against time during the period of particle growth under $30 \mathrm{~nm}$. The growth rates of Class I events measured in this study ranged from 1.79$7.78 \mathrm{~nm} \mathrm{~h}^{-1}$ (average $4.6 \mathrm{~nm} \mathrm{~h}^{-1}$ ), which are comparable to other urban studies such as those conducted in Atlanta (2.86$22.0 \mathrm{~nm} \mathrm{~h}^{-1}$ ) (Woo et al., 2001) and East St. Louis (average $6.7 \mathrm{~nm} \mathrm{~h}^{-1}$ ) (Qian et al., 2007).

\subsection{Case studies of nucleation burst events}

In the above sections, it was shown that nucleation mode particle concentrations were strongly associated with NE/SW winds. Further analysis of the daily variation of particles and wind direction showed that nucleation events with particle growth were usually associated with SW winds, while the nucleation burst events without particle growth were associated with NW winds. In this section, case studies relating to types of three nucleation events are discussed, including: (i) new particle formation by nucleation processes; (ii) a nucleation burst without particle growth; and (iii) the interplay between these two situations.

\subsubsection{Case I - photochemical formation of nucleation particles}

Case I nucleation events were observed during 2829 April 2009. Significant strong nucleation bursts were observed consecutively during these two days (peak $10 \mathrm{~min}$ and hourly averaged $N_{\text {nuc }}$ during the nucleation events were $47 \times 10^{4}$ and $18 \times 10^{4} \mathrm{~cm}^{-3}$, respectively). The time series plots of the particle size distribution and meteorological parameters are illustrated in Fig 10.

During these two days, the highest temperature was about $30^{\circ} \mathrm{C}$ and relative humidity was around $20-40 \%$ at noon. Land and sea breeze wind circulation was observed on both days, with a moderate $\left(\sim 4 \mathrm{~ms}^{-1}\right) \mathrm{SW}$ wind (from inland) dominating in the morning and a moderate NE wind (from the coast) dominating in the afternoon. The variation in concentration of nucleation and Aitken mode particles clearly showed the influence of the nucleation burst on particle number concentrations. In the early morning (06:00-09:00 a.m.) of 28 April 2009, an Aitken mode peak was observed, which could be attributed to traffic exhaust emissions during the morning peak hours. At around 10:00 a.m., a sharp peak of nucleation mode particles was observed and the GMD reached the lowest value of the day $(\sim 8 \mathrm{~nm})$. The wind direction changed to NE at around 01:00 p.m., and turned back to the SW again after midnight. In terms of GMD, the nucleation mode particles were growing into larger particles (GMD increased from 8 to $57 \mathrm{~nm}$ ) until around midnight ( 03:00 a.m. on 29 April 2009). Another nucleation growth event was observed the following day, on 29 April 2009, with similar meteorological conditions to those which were observed on the previous day. However, the concentration of nucleation particles during the nucleation burst was lower

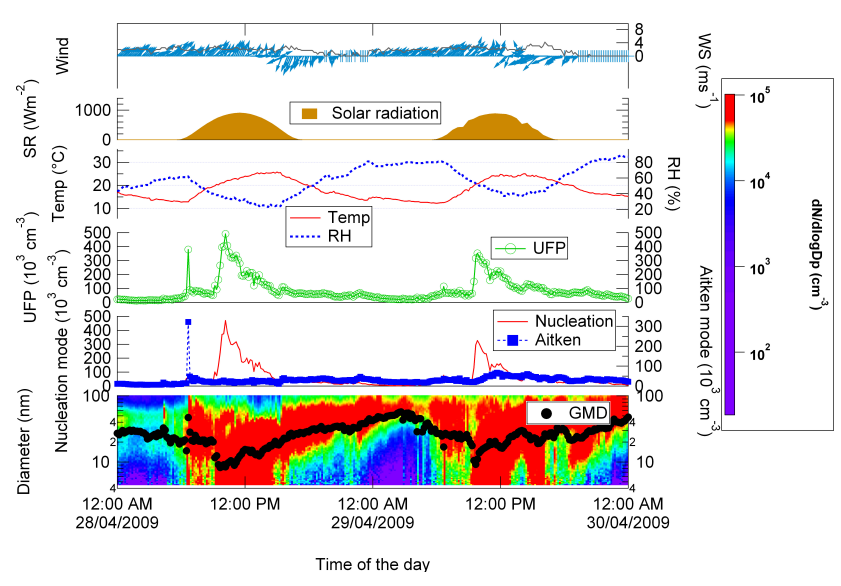

Fig. 10. The nucleation events observed on 28-29 April 2009. From bottom to top, the parameters are: (i) Geometric median diameter (GMD); (ii) Particle number concentration of nucleation and Aitken mode particles; (iii) Particle number concentration of ultrafine particles (UFP); (iv) Temperature and relative humidity; (v) Solar radiation; and (vi) wind direction and speed.

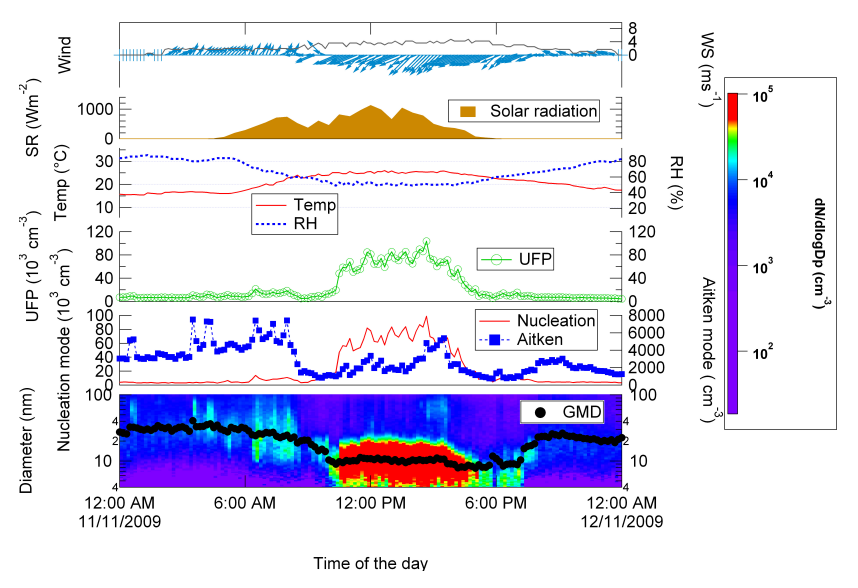

Fig. 11. The nucleation bursts measured on 11 November 2009. From bottom to top, the parameters are: (i) Geometric median diameter (GMD); (ii) Particle number concentration of nucleation and Aitken mode particles; (iii) Particle number concentration of ultrafine particles (UFP); (iv) Temperature and relative humidity; (v) Solar radiation; and (vi) wind direction and speed.

than that observed on the previous day. This result indicated that the higher number of pre-existing Aitken mode particles in the atmosphere served to diminish the nucleation processes.

\subsubsection{Case II - nucleation burst without growth into larger particles}

A Case II nucleation event was observed on 11 November 2009. As shown in Fig. 11, the variation in wind direction was similar to that observed during the Case I nucleation events, whereby land and sea breeze circulation 
was observed, however, the burst of nucleation particles did not appear with the SW wind (associated with local traffic exhaust emissions). Instead, a nucleation burst was observed with the NE wind at $\sim 10: 00 \mathrm{a} . \mathrm{m}$. The GMD dropped from $\sim 30 \mathrm{~nm}$ to $10 \mathrm{~nm}$ and $N_{\text {nuc }}$ increased from $\sim 7.0 \times 10^{3}$ to $10.0 \times 10^{4} \mathrm{~cm}^{-3}$ during the nucleation burst, while $N_{\text {Aitken }}$ did not show any significant variation, ranging from 2 $5 \times 10^{3} \mathrm{~cm}^{-3}$. This plume disappeared at around 06:00 p.m. and GMD rose to $\sim 25 \mathrm{~nm}$. Based on these findings, it was suggested that the plume was not directly emitted from the local traffic exhaust emission or ship emission from the Port of Brisbane, since the particles from vehicle and ship emissions are in the range $20-130 \mathrm{~nm}$ (Morawska et al., 2008) and $60-120 \mathrm{~nm}$ (Sinha et al., 2003), respectively. However, the emissions of $\mathrm{SO}_{2}$ and VOCs from the industrial sources located at the coast could be possible precursors to the formation of new particles by nucleation process. Another possible source of this plume was aircraft emissions from the Brisbane Airport, which was located in a NE direction from the study site. Mazaheri et al. (2009) measured the particle size distribution produced by commercial aircraft at Brisbane Airport and a very distinct peak of nucleation mode particles was observed at around $15 \mathrm{~nm}$. This result was comparable to the average GMD measured during the nucleation burst events in this study, which was $14 \mathrm{~nm}$ (ranging from $8-32 \mathrm{~nm}$ ). In addition, the nucleation burst could be due to the precursors of local emissions which were similar to that in the nucleation growth event or the re-circulated aged plumes belonging to land and sea breeze; however the particle growth process could have been suppressed due to unfavourable conditions, the exact nature of which is not known.

\subsubsection{Case III - interplay between new particle formation and nucleation burst events}

A Case III nucleation event was observed on 15 March 2009. During this study, it was found that particle formation via nucleation processes was associated with SW winds (Fig. 10) and the subsequent particle growth (banana shape of particle size distribution) was usually followed by the presence of a NE wind. In contrast, the nucleation burst events without particle growth were most commonly related to emission sources from the NE (Fig. 11). In some events, a partial banana shape was observed with a SW wind in the morning, but the observation of particle growth was interrupted by a nucleation burst plume from the airport region (Fig. 12).

It can be seen that the nucleation process commenced at 09:00 a.m. and the particles kept growing into Aitken mode particles until 12:00 p.m. (GMD rose from 20 to $35 \mathrm{~nm}$ ). After 12:00 p.m., the wind direction changed to a NE wind and an air plume enriched with nucleation mode particles was observed, which interrupted the observation of a banana shaped progression of the particle size distribution curve. After the interruption, the GMD dropped suddenly to below $20 \mathrm{~nm}$ and several similar cases were also observed during the one year

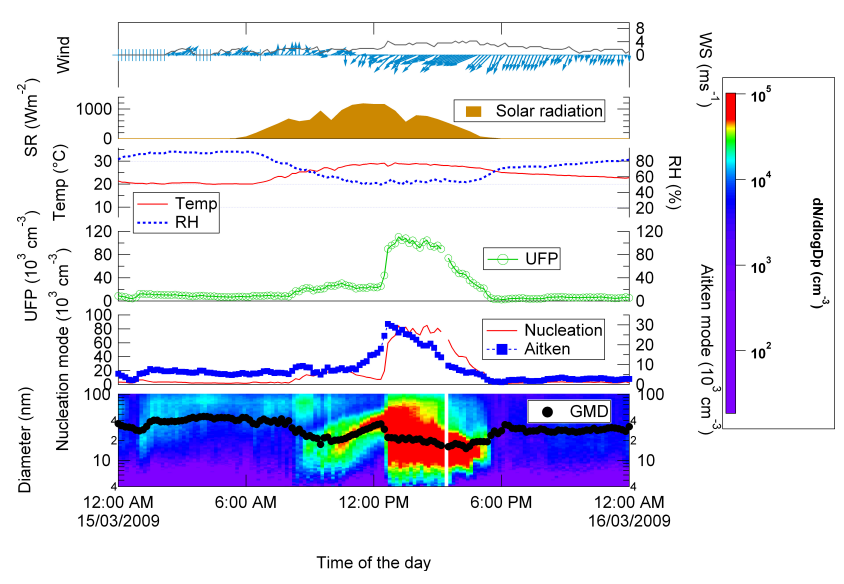

Fig. 12. Contour plot of particle size distribution observed on 15 March 2009. From bottom to top, the parameters are: (i) Geometric median diameter (GMD) and contour plot of size distribution; (ii) Particle number concentration of nucleation and Aitken mode particles; (iii) Particle number concentration of ultrafine particles (UFP); (iv) Temperature and relative humidity; (v) Solar radiation; and (vi) wind direction and speed.

study period at QUT. Overall, the results showed that the nucleation mode particles originated from a variety of sources such as traffic exhaust emission in Brisbane CBD and industrial emissions located NE to Brisbane. Although the observation of a banana shape was interrupted by another air mass, the particle growth process could continue in other regions.

\subsubsection{Source identification}

Gaseous data measured at Pinkenba, which is located near the lower reaches of the Brisbane River (close to the airport, oil refinery and port of Brisbane) and South Brisbane (about $1 \mathrm{~km}$ south to QUT) were used to conduct source analysis. These gaseous measurements were conducted by the Queensland Environmental Protection Agency. Also backtrajectories of the nucleation growth/ burst events were calculated using the HYSPLIT model (Hybrid Single Particle Lagrangian Integrated Trajectory, Version 4.9), in order to trace the origin of the air masses. It should be noted that the grid resolution of the meteorological data used for backtrajectories calculation was $1^{\circ} \times 1^{\circ}$ in latitude and longitude. The data resolution is not accurate enough to trace the detailed air mass passage over the scale of this study region, and therefore, it only provides an indication of the region from which the air mass originated.

The gaseous data available for Pinkenba included CO, $\mathrm{NO}_{2}$, and $\mathrm{SO}_{2}$, while only $\mathrm{CO}$ and $\mathrm{NO}_{2}$ data were available for South Brisbane. The emission ratios of $\mathrm{CO} / \mathrm{NO}_{2}$ and $\mathrm{SO}_{2} / \mathrm{NO}_{2}$ were calculated. On average, the daily minimum of each gaseous species, representing the background value, almost reached zero in our study region. Therefore we did not subtract the background data for the emission 
ratio calculations, as it was negligible. 48-h back trajectories were calculated for the first two sampling hours of each event (see Supplement Figs. S2 and S3) and the average $\mathrm{CO} / \mathrm{NO}_{2}$ and $\mathrm{SO}_{2} / \mathrm{NO}_{2}$ concentrations measured at Pinkenba during the event period were 89.7 and 0.57 , respectively. Overall, the $\mathrm{CO} / \mathrm{NO}_{2}$ ratio exceeded the ratios reported in the 2008/2009 National Pollution Inventory (from www.npi.gov.au, accessed on 15 January 2011) for other sources, such as vehicles (9.7), oil refineries (6.4), ships (0.69) and wildfires (24.6). If the pollution plume was contributed by single source, it was possible to identify the emission source by comparing these emission ratios. For example, the ratio for $\mathrm{SO}_{2} / \mathrm{NO}_{2}(0.57)$ was very close to the ship emission ratio of 0.69 . Although back-trajectory analysis found that almost all trajectories originated from the NE sector during the nucleation burst events, air masses from the NE were influenced by a number of different sources, such as ship, aircraft, oil refinery and the local vehicle emissions. Therefore, it was difficult to identify the specific source/s which contributed to the nucleation burst events. In addition, primary pollution plumes (e.g. $\mathrm{CO}$ and $\mathrm{NO}_{2}$ ) were observed at Pinkenba $1-3 \mathrm{~h}$ prior to the start of the nucleation burst events. From these results, we can conclude that the nucleation burst events were most likely influenced by industrial emissions from the area NE of the sampling site. As mentioned in Sect. 3.4.2, the nucleation burst event could be associated to other possible sources, however the particle growth process could have been suppressed by unfavourable conditions, the exact nature of which is not known

For nucleation growth events, the $\mathrm{CO} / \mathrm{NO}_{2}$ ratio obtained from South Brisbane was 10.2, which is close to the emission inventory data for vehicles (9.7). Back-trajectory analysis also showed that the air masses originated from S-SW directions, except on 21 October 2009, which suggests that vehicle exhaust emissions contributed to the nucleation growth event.

\section{Conclusions}

A year long measurement campaign of the size distribution of ultrafine particles was conducted at subtropical urban area of Brisbane, Australia during 2009. The annual average $N_{\text {UFP }}, N_{\text {Aitken }}$ and $N_{\text {nuc }}$ were $9.3 \times 10^{3}, 3.7 \times 10^{3}$ and $5.6 \times 10^{3} \mathrm{~cm}^{-3}$, respectively. Small seasonal variation in number concentration was observed, with higher particle concentrations observed during the warmer months. Diurnal variation of $N_{\mathrm{UFP}}, N_{\text {Aitken }}$ and $N_{\text {nuc }}$ showed the influence of local traffic exhaust emissions on the particle number concentration during morning peak hours, and elevated nucleation mode particle levels suggested the contribution of new particle formation during the early afternoon. In relation to wind direction, $N_{\text {Aitken }}$ and $N_{\text {nuc }}$ were associated with NE winds, which pointed to the emission sources present at the lower reaches of Brisbane river (such as Brisbane Air- port, the oil refinery and the Port of Brisbane). A broad peak of $N_{\text {Aitken }}$ particles was also observed during SSE to WNW winds, which suggested the influence of local traffic exhaust emissions, with particle size ranging from 30$70 \mathrm{~nm}$. Overall, two major sources of $N_{\text {nuc }}$ were identified in this study, which were new particle formation by nucleation and primary nucleation mode particles emitted from aircraft at Brisbane Airport. New particle formation via nucleation process was frequently observed in this study, and the particle growth rate (average $4.6 \mathrm{~nm} \mathrm{~h}^{-1}$ ) was positively related to the strength of global solar radiation. The nucleation events with particle growth were associated with SW winds which suggested the influence of precursors emitted from traffic exhaust emission in Brisbane city. An interesting question arose during the course of this study regarding the absence of nucleation particle growth in air masses originating from the coast. It may due to lack of nucleation particles precursor associated with coastal air mass. To tackle this question, a further study on the new particle formation, with parallel measurements of particle chemical composition and gaseous pollutants, is needed.

\section{Supplementary material related to this article is available online at: http://www.atmos-chem-phys.net/11/3823/2011/ acp-11-3823-2011-supplement.pdf.}

Acknowledgements. This project was supported by the Australian Research Council and Queensland Transport through Linkage Grant LP0882544. We would also like to thank the Queensland Bureau of Meteorology for providing the meteorological data.

Edited by: X. Querol

\section{References}

Charlson, R. J., Schwartz, S. E., Hales, J. M., Cess, R. D., Coakley Jr., J. A., Hansen, J. E., and Hofmann, D. J.: Climate forcing by anthropogenic aerosols, Science, 255, 423-430, 1992.

Dal Maso, M., Kulmala, M., Riipinen, I., Wagner, R., Hussein, T., Aalto, P. P., and Lehtinen, K. E. J.: Formation and growth of fresh atmospheric aerosols eight years of aerosol size distribution data from SMEAR II, Hyytiälä, Finland, Boreal Environ. Res., 10, 323-336, 2005.

Donaldson, K., Li, X. Y., and MacNee, W.: Ultrafine (nanometre) particle mediated lung injury, J. Aerosol Sci., 29, 553-560, 1998.

Fernández-Camacho, R., Rodríguez, S., de la Rosa, J., Sánchez de la Campa, A. M., Viana, M., Alastuey, A., and Querol, X.: Ultrafine particle formation in the inland sea breeze airflow in Southwest Europe, Atmos. Chem. Phys., 10, 9615-9630, doi:10.5194/acp-10-9615-2010, 2010.

Gao, J., Wang, T., Zhou, X., Wu, W., and Wang, W.: Measurement of aerosol number size distributions in the Yangtze River Delta in China: Formation and growth of particles under polluted conditions, Atmos. Environ., 43, 829-836, 2009. 
Guo, H., Ding, A., Morawska, L., He, C., Ayoko, G., Li, Y., and Hung, W.: Size distribution and new particle formation in subtropical eastern Australia, Environ. Chem., 5, 382-390, 2008.

Hussein, T., Puustinen, A., Aalto, P. P., Mäkelä, J. M., Hämeri, K., and Kulmala, M.: Urban aerosol number size distributions, Atmos. Chem. Phys., 4, 391-411, doi:10.5194/acp-4-391-2004, 2004.

Hussein, T., Karppinen, A., Kukkonen, J., Härkönen, J., Aalto, P. P., Hämeri, K., Kerminen, V.-M., and Kulmala, M.: Meteorological dependence of size-fractionated number concentrations of urban aerosol particles, Atmos. Environ., 40, 1427-1440, 2006.

Johnson, G. R., Ristovski, Z. D., Anna, B. D., Morawska, L.: The hygroscopic behaviour of partially volatilized coastal marine aerosols using the VH-TDMA technique, J. Geophys. Res., 110, D20203, doi:10.1029/2004JD005657, 2005.

Kim, S., Shen, S., Sioutas, C., Zhu, Y., and Hinds, W. C.: Size Distribution and Diurnal and Seasonal Trends of Ultrafine Particles in Source and Receptor Sites of the Los Angeles Basin, Air Waste Manage., 52(33), 2955-2968, 2002.

Kulmala, M.: How Particles Nucleate and Grow, Science, 302, 1000-1001, 2003.

Kulmala, M., Vehkamäki, H., Petäjä, T., Dal Maso, M., Lauri, A., Kerminen, V.-M., Birmili, W., and McMurry, P. H.: Formation and growth rates of ultrafine atmospheric particles: a review of observations, J. Aerosol Sci., 35, 143-176, 2004.

Lee, Y., Lee, H., Kim, M., Choi, C. Y., and Kim, J.: Characteristics of particle formation events in the coastal region of Korea in 2005, Atmos. Environ., 42, 3729-3739, 2008.

Mazaheri, M., Johnson, G. R., and Morawska, L.: Particle and Gaseous Emissions from Commercial Aircraft at Each Stage of the Landing and Takeoff Cycle, Environ. Sci. Technol., 43, 441446, 2009.

Mejía, J. F. and Morawska, L.: An investigation of nucleation events in a coastal urban environment in the Southern Hemisphere, Atmos. Chem. Phys., 9, 7877-7888, doi:10.5194/acp-9-7877-2009, 2009.

Mejíía, J. F., Wraith, D., Mengersen, K., and Morawska, L.: Trends in size classified particle number concentration in subtropical Brisbane, Australia, based on a 5 year study, Atmos. Environ., 41, 1064-1079, 2007.

Meyer, N. K. and Ristovski, Z.: Ternary nucleation as a mechanism for the production of diesel nanoparticles: Experimental analysis of the volatile and hygroscopic properties of diesel exhaust using the volatilization and humidification tandem differential mobility analyzer, Environ. Sci. Technol., 41, 7309-7314, 2007.

Modini, R. L., Ristovski, Z. D., Johnson, G. R., He, C., Surawski, N., Morawska, L., Suni, T., and Kulmala, M.: New particle formation and growth at a remote, sub-tropical coastal location, Atmos. Chem. Phys., 9, 7607-7621, doi:10.5194/acp-9-7607-2009, 2009.

Moore, K. F., Ning, Z., Ntziachristos, L., Schauer, J. J., and Sioutas, C.: Daily variation in the properties of urban ultrafine aerosol Part I: Physical characterization and volatility, Atmos. Environ., 41, 8633-8646, 2007.

Morawska, L., Thomas, S., Bofinger, N., Wainwright, D., and Neale, D.: Comprehensive characterization of aerosols in a subtropical urban atmosphere: Particle size distribution and correlation with gaseous pollutants, Atmos. Environ., 32, 2467-2478, 1998.
Morawaska, L., Ristovski, Z., Jayaratne, E. R., Keogh, D. U., and Ling, X.: Ambient nano and ultrafine particles from motor vehicle emissions: Characteristics, ambient processing and implications on human exposure, Atmos. Environ., 42, 8113-8138, 2008.

O’Dowd, C. D., McFiggans, G., Greasey, D. J., Pirjola, L., Hoell, C., Smith, M. H., Allan, B. J., Plane, J. M. C., Heard, D. E., Lee, J. D., Pilling, M. J., and Kulmala, M.: On the photochemical production of new particles in the coastal boundary layer, Geophys. Res. Lett., 26, 1707-1710, 1999.

Olivares, G., Johansson, C., Strom, J., and Hasson, H.-C.: The role of ambient temperature for particle number concentrations in a street canyon, Atmos. Environ., 41(10), 2145-2155, 2007.

Park, K., Park, J.Y., Kwak, J-H., Cho, G.N., Kim, J.-S.: Seasonal and diurnal variations of ultrafine particle concentration in urban Gwangju, Korea: Observation of ultrafine particle events, Atmos. Environ., 42, 788-799, 2008.

Pérez, N., Pey, J., Cusack, M., Reche, C., Querol, X., Alastuey, A., and Viana, M.: Variability of Particle Number, Black Carbon, and $\mathrm{PM}_{10}, \mathrm{PM}_{2.5}$, and PM1 Levels and Speciation: Influence of Road Traffic Emissions on Urban Air Quality, Aerosol Sci. Technol., 44, 487-499, 2010.

Pey, J., Rodíguez, S., Querol, X., Alastuey, A., Moreno, T., Putaud J. P., and Van Dingenen, R.: Variations of urban aerosols in the western Mediterranean, Atmos. Environ., 42, 9052-9062, 2008.

Pey, J., Querol, X., Alastuey, A., Rodíguez, S., Putaud, J. P., and Van Dingenen, R.: Source apportionment of urban fine and ultrafine particle number concentration in a Western Mediterranean city, Atmos. Environ., 43, 4407-4415, 2009.

Ristovski, Z. D., Suni, T., Kulmala, M., Boy, M., Meyer, N. K., Duplissy, J., Turnipseed, A., Morawska, L., and Baltensperger, U.: The role of sulphates and organic vapours in growth of newly formed particles in a eucalypt forest, Atmos. Chem. Phys., 10, 2919-2926, doi:10.5194/acp-10-2919-2010, 2010.

Rodríguez, S., Cuevas, E., González, Y., Ramos, R., Romero, P.M., Pérez, N., Querol, X., Alastuey, A.: Influence of sea breeze circulation and road traffic emissions on the relationship between particle number, black carbon, $\mathrm{PM}_{1}, \mathrm{PM}_{2.5}$ and $\mathrm{PM}_{2.5-10}$ concentrations in a coastal city, Atmos. Environ., 42, 6523-6534, 2008.

Qian, S., Sakurai, H., and McMurry, P. H.: Characteristics of regional nucleation events in urban East St. Louis, Atmos. Environ., 41, 4119-4127, 2007.

Sinha, P., Hobbs, P. V., Yokelson, R. J., Christian, T. J., Kirchstetter, T. W., and Bruintjes, R.: Emissions of trace gases and particles from two ships in the southern Atlantic Ocean, Atmos. Environ., 37, 2139-2148, 2003.

Suni, T., Kulmala, M., Hirsikko, A., Bergman, T., Laakso, L., Aalto, P. P., Leuning, R., Cleugh, H., Zegelin, S., Hughes, D., van Gorsel, E., Kitchen, M., Vana, M., Hõrrak, U., Mirme, S., Mirme, A., Sevanto, S., Twining, J., and Tadros, C.: Formation and characteristics of ions and charged aerosol particles in a native Australian Eucalypt forest, Atmos. Chem. Phys., 8, 129-139, doi:10.5194/acp-8-129-2008, 2008.

Vehkamäki, H., Dal Maso, M., Hussein, T., Flanagan, R., Hyvärinen, A., Lauros, J., Merikanto, P., Mönkkönen, M., Pihlatie, K., Salminen, K., Sogacheva, L., Thum, T., Ruuskanen, T. M., Keronen, P., Aalto, P. P., Hari, P., Lehtinen, K. E. J., Rannik, Ü., and Kulmala, M.: Atmospheric particle formation events at 
Värriö measurement station in Finnish Lapland 1998-2002, Atmos. Chem. Phys., 4, 2015-2023, doi:10.5194/acp-4-2015-2004, 2004.

Weber, R. J., Moore, K., Kapustin, V., Clarke, A., Mauldin, R. L., Kosciuch, E., Cantrell, C., Eisele, F., Anderson, B., and Thornhill, L.: Nucleation in the equatorial pacific during PEM-tropics B: Enhanced boundary layer $\mathrm{H}_{2} \mathrm{SO}_{4}$ but no particle production: NASA global tropospheric experiment Pacific Exploratory Mission in the tropics phase B, Part 1: Measurement and analyses (PEM-Tropics B), J. Geophys. Res., 106, 32767-32776, 2001.
Woo, K. S., Chen, D. R., Pui, D. Y. H., and McMurry, P. H.: Measurements of Atlanta aerosol size distributions: observations of ultrafine particle events, Aerosol Sci. Technol., 34, 75-87, 2001.

Wu, Z., Hu, M., Lin, P., Liu, S., Wehner, B., and Wiedensohler, A.: Particle number size distribution in the urban atmosphere of Beijing, China, Atmos. Environ., 42, 7967-7980, 2008. 